\title{
Article \\ Age-Related Intrinsic Functional Connectivity Changes of Locus Coeruleus from Childhood to Older Adults
}

\author{
Inuk Song ${ }^{1}$, Joshua Neal ${ }^{1}$ and Tae-Ho Lee ${ }^{1,2, *(D)}$ \\ 1 Department of Psychology, Virginia Tech, Blacksburg, VA 24060, USA; psyence221b@vt.edu (I.S.); \\ jneal96@vt.edu (J.N.) \\ 2 School of Neuroscience, Virginia Tech, Blacksburg, VA 24060, USA \\ * Correspondence: taehol@vt.edu
}

check for updates

Citation: Song, I.; Neal, J.; Lee, T.-H. Age-Related Intrinsic Functional Connectivity Changes of Locus Coeruleus from Childhood to Older Adults. Brain Sci. 2021, 11, 1485. https://doi.org/10.3390/brainsci 11111485

Academic Editor: Oxana Eschenko

Received: 8 October 2021

Accepted: 7 November 2021

Published: 10 November 2021

Publisher's Note: MDPI stays neutral with regard to jurisdictional claims in published maps and institutional affiliations.

Copyright: (C) 2021 by the authors. Licensee MDPI, Basel, Switzerland. This article is an open access article distributed under the terms and conditions of the Creative Commons Attribution (CC BY) license (https:/ / creativecommons.org/licenses/by/ $4.0 /)$.

\begin{abstract}
The locus coeruleus is critical for selective information processing by modulating the brain's connectivity configuration. Increasingly, studies have suggested that LC controls sensory inputs at the sensory gating stage. Furthermore, accumulating evidence has shown that young children and older adults are more prone to distraction and filter out irrelevant information less efficiently, possibly due to the unoptimized LC connectivity. However, the LC connectivity pattern across the life span is not fully examined yet, hampering our ability to understand the relationship between LC development and the distractibility. In this study, we examined the intrinsic network connectivity of the LC using a public fMRI dataset with wide-range age samples. Based on LC-seed functional connectivity maps, we examined the age-related variation in the LC connectivity with a quadratic model. The analyses revealed two connectivity patterns explicitly. The sensory-related brain regions showed a positive quadratic age effect (u-shape), and the frontal regions for the cognitive control showed a negative quadratic age effect (inverted $u$-shape). Our results imply that such age-related distractibility is possibly due to the impaired sensory gating by the LC and the insufficient top-down controls by the frontal regions. We discuss the underlying neural mechanisms and limitations of our study.
\end{abstract}

Keywords: locus coeruleus; distractibility; neurodevelopment; functional connectivity

\section{Introduction}

The locus coeruleus (LC) is a small nucleus located deep in the brainstem and a major source of norepinephrine. The LC releases norepinephrine to almost the entire brain throughout its efferent projections according to both the phasic and tonic firing of LC neurons, thereby the LC is one of the primary brain regions critical for selective information processing by changing the brain's configurations [1-10]. Recent studies consistently have suggested that the LC functionally controls sensory inputs at the early sensory gating stage by changing the brain's connectivity configurations [11-13]. For instance, the stimulated LC changes its neural communication with the basolateral nucleus of the amygdala [14] and thalamus $[15,16]$, which receive the majority of sensory information for the further in-depth cognitive process. Similarly, direct chemogenetic stimulation of LC immediately changes neural connectivity configurations, especially for the intrinsic networks that mediate the bottom-up sensory process, including the primary sensory and salience networks [17]. That is, the LC plays a role in controlling sensory flows in the brain, suggesting that impaired processing selectivity is possibly due to the failure of communication between the LC and sensory regions that introduces the sensory overflows in the brain.

Human imaging studies also imply that the LC system changes the bottom-up process at the early sensory-perceptual stage to prioritize important information. For example, the induced phasic LC activity by arousing or stressful stimuli at the early sensory-perceptual level increases the initial selective attention processes [7-9] and attentional control [18,19]. Finally, such initial LC-induced selectivity at the early sensory stage carries over to the 
late cognitive processing such as memory encoding [20], memory consolidation [5,21], and decision making [22]. Thus, the interrupted LC activity has been often examined in individuals with conditions associated with hyperarousal and attentional vigilance such as attention-deficit hyperactivity disorder (ADHD) [23-25], and posttraumatic stress disorder (PTSD) [26-28].

Recent studies also showed that older adults, who are more prone to distraction, exhibit interrupted LC connectivity [29-36]. For instance, older adults showed the hyperconnectivity of the LC with the primary sensory networks compared to younger adults as well as the hypo-functional coupling with the salience network [8], suggesting that the impaired connectivity between the sensory regions and LC induces sensory overflows in the brain and thus the salience network fails to guide attention appropriately. As a result, there is an unnecessary depletion of limited neural resources in the brain leading the executive frontal systems to not maintain goal-directed processes due to irrelevant stimuli that should be ignored earlier.

However, children's developmental trajectories of LC connectivity have not been characterized yet. Healthy young children also show behavioral propensity to react to irrelevant information combined with heightened impulsivity [37-39]. This distractibility in children is possibly due to their less-developed LC function during their early developmental stage, such that structural studies have demonstrated that structural integrity of the LC increases with age gradually and then declines after the peak (i.e., inverted U-shaped curvilinear trend) [40-42]. Furthermore, studies suggest that brain development occurs first in the primary sensory bottom-up regions from early childhood with a progressively maturing top-down frontal system [43,44]. Thus, the unbalanced brain development in childhood between not-fully-developed LC and matured sensory network regions possibly leads children to fail at moderating sensory overflows in the brain.

Considering accumulating evidence indicating that the LC plays an essential role in the brain's processing selectivity, the overarching objectives of the current study are to provide a full description of LC connectivity pattern across the lifespan from early childhood to older adulthood. Given the brain development findings [40-42] and heightened distractibility in early childhood and older adults [7,8,37-39], we hypothesized that children and older adults, compared to younger adults and middle adults, show increased functional connectivity of the LC with the primary sensory regions (i.e., quadratic or ushape curve), indicating that those two age groups have unnecessarily higher sensory sensitivity intrinsically even without task-induced activity (i.e., resting-state fMRI). We hypothesized the quadratic age effects because the development of structural integrity in the LC follows a curvilinear trend [40] and behavioral performances also follow the inverted U-shape in general [45]. To this end, we used cross-sectional samples (age-ranged between 8 and 83 years) and examined intrinsic functional connectivity of the LC associated with age changes based on the resting-state fMRI data. We especially examined the intrinsic network connectivity of the LC based on the resting-state fMRI signal as it reflects general intrinsic neural architecture of brain development at the time of the brain scan, rather than a moment-by-moment task-specific neural response [8,46-49].

\section{Materials and Methods}

\subsection{Data Characteristics}

The present study was carried out using resting-state fMRI data from the enhanced Nathan Kline Institute (NKI)-Rockland project [50]. The dataset was initially downloaded through the Mind Research Network's collaborative informatics and neuroimaging suite (COINS) [51]. We only included individuals with full-coverage of both T1 and EPI, and without severe motions (framewise displacement, $F D>0.5 \mathrm{~mm}$ ), which resulted in 595 samples $(M=39.47$ years, $S D=20.51$, range $=8-83,63.36 \%$ females; see Figure $S 1$ in Supplementary Information). In this research, considering the previous studies [7,8,21,35], we referred to age groups approximately as follows: early childhood $(<12)$, adolescents $(12-20)$, younger adults $(20-40)$, middle adults $(40-60)$, and older adults $(>60)$. All indi- 
vidual data were collected in the same scanning protocol with a 32-channel head-coil for the high-resolution structural image (T1-MPRAGE; TR $=1950 \mathrm{~ms}$; $\mathrm{TE}=2.52 \mathrm{~ms}$; FA $=9^{\circ}$; 1 -mm isotropic voxel; FOV $=256 \mathrm{~mm}$ ) and EPI image (364 volumes; 2 -mm isotropic voxel, 64 slices; $\mathrm{TR}=1400 \mathrm{~ms} ; \mathrm{TE}=30 \mathrm{~ms} ; \mathrm{FA}=65^{\circ} ;$ matrix size $=112 \times 112 ; \mathrm{FOV}=224 \mathrm{~mm}$ ).

\subsection{Preprocessing}

Preprocessing was performed using the FMRIB Software Library (FSL) combined with ICA-AROMA [52] and ANTs [53], including skull stripping and tissue mask segmentation (CSF/WM/GM) after bias-field correction for structural images, and first 10-volumes cut, motion correction, slice-timing correction, intensity normalization, regressing out CSF/WM with individually segmented masks, ICA-denoising (corrected mean FD $=0.02 \mathrm{~mm}$, range $=0.01-0.14 \mathrm{~mm}$; Figure $1 \mathrm{~B}$ ) and registration to standard Montreal Neurological Institute (MNI) 2-mm brain template for functional images. To avoid possible signal mixture of LC region with neighboring regions such as periaqueductal gray or ventral tegmental area, we skipped the signal smoothing step.
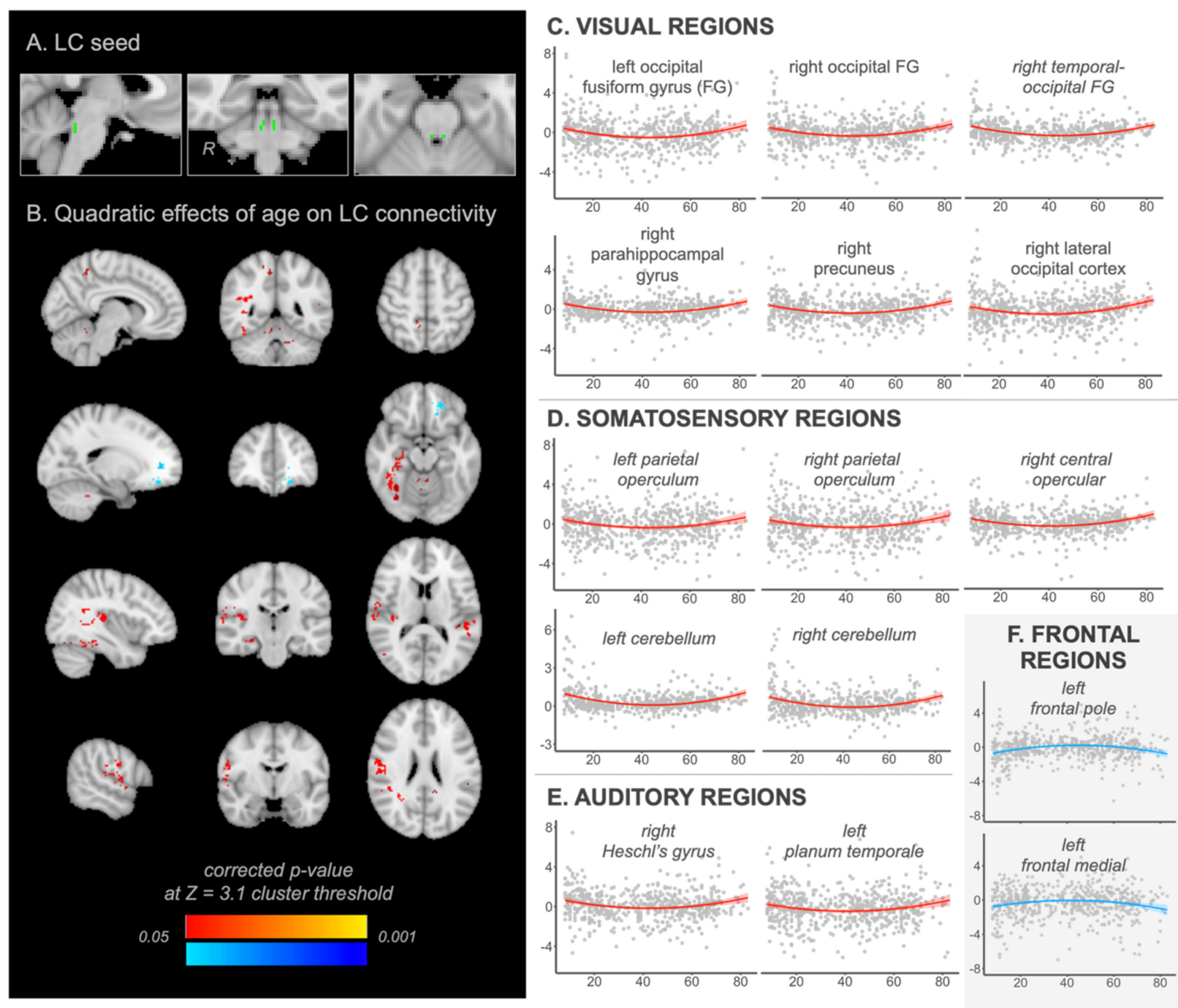

Figure 1. (A) LC seed mask (B) whole brain maps showing a quadratic effect of age on LC connectivity. Red: corrected $p$-value for the positive quadratic effect (u-shape curve). Blue: corrected $p$-value for the negative quadratic effect (inverted u-shape curve). Regions in (C) the visual network (D) somatosensory network (E) auditory network and (F) frontal network. $Y$-axis: LC connectivity strength with each region (z-statistics); $X$-axis: age (years). 


\subsection{Whole-Brain Multiple Regression Analysis for Age-Related Changes in LC Connectivity}

We first extracted the mean time-series of LC activity from the preprocessed image on each individual's non-smoothed native space using a standard structural LC mask (Figure 1A) [54]. Using this LC time course, a multiple regression analysis was then performed to estimate individual level LC-seed functional connectivity maps (z-transformed). Finally, changes of LC connectivity with age were estimated at the whole-brain level using a multiple regression model. Consistent with our main hypothesis, we examined the age-related variation in the LC connectivity with a quadratic model (i.e., $a g e^{2}$ and age):

$$
\text { LC connectivity }(Y)=\text { Intercept }+\beta_{1}\left(\text { age }^{2}\right)+\beta_{2}(\text { age })+\beta_{3} \text { (gender) }
$$

In the model, we included gender in the design matrix as nuisance regressors to attenuate gender effects. The group-level whole-brain connectivity model was tested using non-parametric permutation-based inference (FSL's randomise tool with 5000 permutations) [55] with cluster threshold at $Z=3.1(p=0.001)$ and an FWE-corrected $p$ at 0.05 .

\section{Results}

Whole-brain multiple regression analysis on the LC connectivity revealed significant regions that have quadratic relationships with age. As expected, a significant positive quadratic relationship of age was found for connectivity between the LC and several other regions that are mainly associated with the sensory process (i.e., visual, somatosensory, auditory; Figure 1C-E). For example, visual processing regions along the ventral occipitotemporal and dorsal visual pathways including the occipital and temporal fusiform gyrus, parahippocampal gyrus, and precuneus [56], decrease functional connectivity with the LC gradually from early childhood years to a low around 40-45 years old, and then increase according to age (Figure 1C). The parietal operculum extended to the central region and the cerebellum also showed the same u-shape curve of age effects on the LC connectivity (Figure 1D). These regions are known as the secondary somatosensory cortex involved in tactile and pain sensations [57]. Finally, we found that regions in the primary auditory network including Heschl's gyrus extended to the planum temporale [58] showed the same quadratic age relationship on the LC connectivity (Figure 1E). To sum, these results indicated that during their respective development stages, children and older adults have increased sensory interaction with the LC in the brain.

Importantly, we also found that there was a significant age-related negative quadratic effect on the LC connectivity for the frontal regions (Figure 1F). The frontal pole extended to the frontal medial cortex, known to be involved in action monitoring and cognitive control (e.g., action selection) [59], showed lower LC connectivity during the early childhood and older adulthood years than younger and middle adulthood years (i.e., inverted U-shaped curve). In other words, the LC has stronger connectivity with the frontal regions during younger and middle adulthood years compared to both developing children and older adults. All significant regions of LC connectivity associated with ages are displayed in Table 1 and Figure S2 in Supplementary Information. The group-mean of LC connectivity across ages is in Supplementary Information (Figure S3). 
Table 1. Significant brain regions of quadric age effects (cluster threshold at $Z=3.1$ and corrected $p$-value at 0.05 after 5000 permutation) on the LC seed-based whole-brain connectivity analysis. $t=\mathrm{t}$-value; $\mathrm{H}=$ hemisphere; $\mathrm{BA}=\mathrm{Broadman}$ area; Region labeling is based on Harvard-Oxford atlas.

\begin{tabular}{|c|c|c|c|c|c|c|c|}
\hline & \multirow{2}{*}{$t$} & \multirow{2}{*}{$\mathbf{H}$} & \multirow{2}{*}{ BA } & \multicolumn{3}{|c|}{ MNI } & \multirow{2}{*}{ Note } \\
\hline & & & & $x$ & $y$ & $z$ & \\
\hline \multicolumn{8}{|l|}{ Positive quadratic age effect } \\
\hline Parahippocampal gyrus & 4.79 & $\mathrm{R}$ & 36 & 30 & -22 & -16 & Visual \\
\hline Precuneus & 4.71 & $\mathrm{R}$ & 7 & 8 & -48 & 52 & Visual \\
\hline Lateral occipital gyrus & 4.37 & $\mathrm{R}$ & 19 & 46 & -66 & 18 & Visual \\
\hline Fusiform gyrus, temporal occipital & 4.52 & $\mathrm{R}$ & 37 & 40 & -48 & -22 & Visual \\
\hline \multirow[t]{2}{*}{ Fusiform gyrus, occipital } & 4.16 & $\mathrm{~L}$ & 19 & -28 & -78 & -12 & Visual \\
\hline & 4.07 & $\mathrm{R}$ & 37 & 34 & -70 & -16 & Visual \\
\hline \multirow[t]{2}{*}{ Cerebellum } & 4.58 & $\mathrm{R}$ & - & 4 & -56 & -18 & Somatosensory \\
\hline & 4.17 & $\mathrm{~L}$ & - & -4 & -48 & -16 & Somatosensory \\
\hline Opercular cortex, central & 4.25 & $\mathrm{R}$ & 6 & 54 & -2 & 6 & Somatosensory \\
\hline \multirow[t]{2}{*}{ Operculum, parietal } & 3.81 & $\mathrm{~L}$ & 13 & -46 & -34 & 20 & Somatosensory \\
\hline & 3.27 & $\mathrm{R}$ & 13 & 42 & -26 & 18 & Somatosensory \\
\hline Heschl's Gyrus & 4.54 & $\mathrm{R}$ & 41 & 38 & -24 & 12 & Auditory \\
\hline Planum temporale & 3.33 & $\mathrm{~L}$ & 41 & -42 & -34 & 12 & Auditory \\
\hline \multicolumn{8}{|l|}{ Negative quadratic age effect } \\
\hline Frontal pole & 3.897 & $\mathrm{~L}$ & 10 & -28 & 52 & 2 & Frontal \\
\hline Frontal medial cortex & 3.160 & $\mathrm{~L}$ & 11 & -4 & 40 & -18 & Frontal \\
\hline
\end{tabular}

\section{Discussion}

The goal of the current study was to provide a full description of age-related changes in the intrinsic LC connectivity by adopting cross-sectional fMRI data from early childhood to older adulthood. Specifically, given the findings that children and older adults are prone to distraction [7,8,29-39], we hypothesized that the LC, a critical region for selective information processing in the brain, showed distinct connectivity patterns with other regions in early childhood and older adulthood compared to younger and middle adults who show more stable attentional ability. As a result, we found that the LC's connectivity with sensory regions showed a U-shaped curve pattern across ages, indicating that the sensory regions exhibit highly increased intrinsic connectivity with the LC in both early childhood and late older adulthood. The current findings suggest that such age-related distractibility is possibly due to the insufficient sensory gating process by the LC. Most importantly, the current analyses also revealed that the LC connectivity with the frontal regions showed an inverted U-shaped curve pattern. That is, while the sensory network regions are connected to the LC excessively, the frontal network regions have decreased connectivity with the LC, implying that the frontal control regions cannot handle the sensory overflows appropriately. These results are similar to the previous finding in that the LC showed curvilinear connectivity patterns with other cortical regions as a function of age [41]. However, the previous study's curvilinear patterns were cubic mostly, and most of them appeared in the frontal lobe rather than throughout the brain. In addition, our results showed two distinctive connectivity change patterns and covered a wider range of ages including early childhood. This is the first full description of how the LC configuration changes from early childhood to older adulthood, informing the LC model of distractibility in both children and older adults.

The current findings implied that the increased distractibility at both early and late developmental stages is due to not only the LC-related excessive sensory overflows but also the lower LC connectivity in the frontal regions. However, although the observed patterns of LC connectivity for sensory and frontal regions are the same for both children and older adult groups, the underlying neural mechanisms for the attentional deficits regarding the LC connectivity may not be identical given structural differences in the developmental trajectory. At the early developmental stage, the primary brain structures 
including sensory cortex and subcortical bottom-up network regions mature first while the higher-cognitive prefrontal regions are still in the process of developing $[43,60]$, whereas the LC does not yet fully function [40-42,61]. Thus, it is possible that the LC fails to appropriately prioritize sensory inputs inflow from the fully developed sensory networks, leading to sensory overflows in the children's brain. That is, the immature LC which cannot control sensory inputs appropriately, and the overflow leads to the unnecessarily increased functional connectivity between LC and sensory regions. In addition, the LC fails to initiate the frontal control region for the flux of sensory inputs in the children's brain, leading to the decreased functional connectivity. In contrast, given the finding of prominent age-related decline in brain volume as well as functional response of the prefrontal areas compared to other regions [62,63], the increased distractibility in the older adults is more derived from the decreased frontal functionality in controlling sensory inputs. Although the sensory networks also showed cortical thinning with the frontal cortex in older adults [64], evidence indicates decreased sensory sensitivity in the brain at the early sensory gating stage. For instance, older adults have less activations in the visual and auditory cortex under the passive stimuli presentation [65] suggesting that older adults have less sensory-perceptual sensitivity in terms of change detection. Therefore, the LC can still handle the reduced primary sensory processing even when the LC is functionally degraded, but the prominently decreased frontal control regions are overwhelmed by even less sensory inputs. It may cause the increased functional connectivity between the LC and the sensory and the decreased connectivity between the LC and the frontal control region.

In the current study, we mainly examined the LC-centered neural connectivity across age which may possibly serve as the underlying neural mechanism for the attentional distractibility often observed at both early and late developmental stages. However, the suggested LC circuit mechanism sheds light on understanding other late cognitive process and attention-related mental disorders, as the current result showed the intrinsic connectivity pattern of the $\mathrm{LC}$ as a function of age, and it can be used as a framework to interpret the LC-involved neural activities. For instance, the attentional process involved in memory encoding. Some studies revealed that the LC is associated with memory encoding $[5,20]$ and older adults with reduced LC structure showed poorer memory encoding [66]. With regard to these studies, our results imply that the intrinsic LC-parahippocampal gyrus connection is a pivotal neural circuit of memory encoding in aging. As another example, ADHD is regarded as a mental illness characterized by hyperarousal and attentional vigilance [24]. As described above, it is known that the LC is associated with ADHD. Our results may bring insight into understanding and/or predicting the neural underpinnings of ADHD developmental trajectories given that there have not been many studies involving adults with ADHD [67].

However, there are some limitations in the current study. We examined intrinsic functional connectivity of the LC using the non-task based intrinsic neural network (i.e., resting-state fMRI) based on the previous behavioral observations of the increased attentional distractibility in the early childhood and older adulthood. Thus, our observation might be suboptimal to link actual attentional ability and LC-associated neural configurations compared to task-based assessments in the laboratory with various attentional tasks, which measure attentional selectivity and control more directly. We conjecture that additional attention-related brain regions and/or networks, such as dorsolateral prefrontal cortex, anterior cingulate cortex [68,69], and frontoparietal network [70,71], can be more involved in cognitive processing and the interactions between the additional regions and the LC can be estimated. Future research is needed to employ task-based assessments to link the attentional ability and LC connectivity changes across ages.

Moreover, it is important to note that the LC is an exceptionally small structure in the brainstem, and thus it is difficult to locate its location and signal in an individual brain. Although we used the standard LC structure mask and extracted LC time-series (i.e., LC's neural activity) from non-smoothed EPI image on the native space [72] combined with the ICA-denoising $[5,7,9]$ to increase LC signal fidelity in the connectivity estimation, there 
are several ways to increase LC signal reliability. First, an additional T1-FSE scan (i.e., structural MRI scanning for norepinephrine neuron) can be used. With a 2-3 min duration in a scan, it allows to locate the individual neuromelanin structure such as substantia nigra, ventral tegmental area, and the LC on the native space [30,73]. Recent studies also suggested that T1 structural MRI with magnetization transfer (MT-weighted MRI) can distinguish the LC from its surroundings [74,75]. Unfortunately, the current study is based on public data and thus we could not utilize additional LC structure images given the pre-determined imaging protocols and collections. Secondly, extracting a seed signal without smoothing on the native space can minimize the mixture of signals between nearby regions [8]. In our analysis, we used the non-smoothed LC time-series as a seed region neural activity. Thirdly, recent studies suggested a comprehensive mask [76] and a highconfidence meta mask of the LC by aggregating multiple LC masks [77]. For example, Dahl and colleagues yielded the high confidence mask by aggregating 6 LC masks $[40,78-80]$ and showed that the meta mask captured LC-related hyperintensity accurately. Thus, it would also be beneficial to use the comprehensive or meta mask in the future study. Lastly, the LC is often confounded by physio artifacts such as cardiac pulsation and thus it is helpful to run additional physiological denoising [81]. Although the ICA-denoising is a promising approach to mitigate physiological influence at the global level, the individualbased physiological denoising process using respiration and cardiac pulse signal can be more focal and direct to the brainstem signal fluctuation correction [81]. In this instance we could not use individual specific LC masks or physiological noise correction. Therefore, in future work, it would be beneficial to utilize the LC structural scan and physiological data collection.

\section{Conclusions}

We analyzed the age-related LC connectivity changes with a quadratic model. A positive quadratic relationship of age was found for connectivity between the LC and sensory regions. A negative quadratic relationship was found between LC and frontal regions. Our results suggest that the increased distractibility at both early and late developmental stages is due to not only the LC-related excessive sensory overflow but also the lower LC connectivity with the frontal regions. It is noteworthy that the LC showed two distinctive connectivity change patterns as a function of age. Furthermore, we revealed the children's LC connectivity configuration that has not been characterized yet. Our findings are the first full description of how the LC connectivity configuration changes across age.

Supplementary Materials: The following are available online at https: / www.mdpi.com/article/ 10.3390/brainsci11111485/s1, Figure S1: Age distribution.; Figure S2: The whole-brain map of LC seed-based functional connectivity showing the quadratic effects of age.; Figure S3: Group-level mean LC connectivity without age consideration.

Author Contributions: Conceptualization, I.S. and T.-H.L.; methodology, T.-H.L.; software, I.S.; validation, I.S., J.N. and T.-H.L.; formal analysis, T.-H.L.; investigation, I.S. and T.-H.L.; resources, J.N. and T.-H.L.; data curation, I.S.; writing-original draft preparation, I.S. and T.-H.L.; writingreview and editing, J.N. and T.-H.L.; visualization, I.S.; supervision, T.-H.L.; project administration, T.-H.L.; funding acquisition, T.-H.L. All authors have read and agreed to the published version of the manuscript.

Funding: This work was done based on research supports by Virginia Tech startup funds (to T.-H.L.).

Institutional Review Board Statement: All data were acquired in accordance with Nathan-KlineInstitute IRB guidelines (Phase I \#226781 and Phase II \#239708).

Informed Consent Statement: Informed consent was obtained from all participants at the data collection stage in the enhanced NKI project.

Data Availability Statement: The enhanced NKI data are available in COINS (https:/ / coins.trendscenter. org/) and the NITRC (https:/ / fcon_1000.projects.nitrc.org/indi/pro/nki.html).

Conflicts of Interest: The authors declare no conflict of interest. 


\section{References}

1. Aston-Jones, G.; Cohen, J.D. An integrative theory of locus coeruleus-norepinephrine function: Adaptive gain and optimal performance. Annu. Rev. Neurosci. 2005, 28, 403-450. [CrossRef] [PubMed]

2. Berridge, C.W.; Waterhouse, B.D. The locus coeruleus-noradrenergic system: Modulation of behavioral state and state-dependent cognitive processes. Brain Res. Brain Res. Rev. 2003, 42, 33-84. [CrossRef]

3. Carter, M.E.; Yizhar, O.; Chikahisa, S.; Nguyen, H.; Adamantidis, A.; Nishino, S.; Deisseroth, K.; de Lecea, L. Tuning arousal with optogenetic modulation of locus coeruleus neurons. Nat. Neurosci. 2010, 13, 1526-1533. [CrossRef] [PubMed]

4. Chen, W. Stimulant Drugs and ADHD: Basic and Clinical Neuroscience; Solanto, M., Arnsten, A., Castellanos, F.X., Eds.; University of Oxford Press: Oxford, UK, 2001; p. 410. ISBN 0-19-513371-4.

5. Clewett, D.V.; Huang, R.; Velasco, R.; Lee, T.H.; Mather, M. Locus Coeruleus Activity Strengthens Prioritized Memories Under Arousal. J. Neurosci. 2018, 38, 1558-1574. [CrossRef]

6. Coronel-Oliveros, C.; Castro, S.; Cofré, R.; Orio, P. Structural features of the human connectome that facilitate the switching of brain dynamics via noradrenergic neuromodulation. Front. Comput. Neurosci. 2021, 15, 61. [CrossRef]

7. Lee, T.H.; Greening, S.G.; Ueno, T.; Clewett, D.; Ponzio, A.; Sakaki, M.; Mather, M. Arousal increases neural gain via the locus coeruleus-norepinephrine system in younger adults but not in older adults. Nat. Hum. Behav. 2018, 2, 356-366. [CrossRef]

8. Lee, T.H.; Kim, S.H.; Katz, B.; Mather, M. The Decline in Intrinsic Connectivity Between the Salience Network and Locus Coeruleus in Older Adults: Implications for Distractibility. Front. Aging Neurosci. 2020, 12, 2. [CrossRef]

9. Lee, T.H.; Sakaki, M.; Cheng, R.; Velasco, R.; Mather, M. Emotional arousal amplifies the effects of biased competition in the brain. Soc. Cogn. Affect. Neurosci. 2014, 9, 2067-2077. [CrossRef]

10. Mather, M.; Harley, C.W. The Locus Coeruleus: Essential for Maintaining Cognitive Function and the Aging Brain. Trends Cogn. Sci. 2016, 20, 214-226. [CrossRef]

11. McBurney-Lin, J.; Lu, J.; Zuo, Y.; Yang, H. Locus coeruleus-norepinephrine modulation of sensory processing and perception: A focused review. Neurosci. Biobehav. Rev. 2019, 105, 190-199. [CrossRef]

12. Devilbiss, D.M.; Waterhouse, B.D.; Berridge, C.W.; Valentino, R. Corticotropin-releasing factor acting at the locus coeruleus disrupts thalamic and cortical sensory-evoked responses. Neuropsychopharmacology 2012, 37, 2020-2030. [CrossRef]

13. Waterhouse, B.D.; Navarra, R.L. The locus coeruleus-norepinephrine system and sensory signal processing: A historical review and current perspectives. Brain Res. 2019, 1709, 1-15. [CrossRef]

14. Fast, C.D.; McGann, J.P. Amygdalar gating of early sensory processing through interactions with locus coeruleus. J. Neurosci. 2017, 37, 3085-3101. [CrossRef]

15. Rodenkirch, C.; Liu, Y.; Schriver, B.J.; Wang, Q. Locus coeruleus activation enhances thalamic feature selectivity via norepinephrine regulation of intrathalamic circuit dynamics. Nat. Neurosci. 2019, 22, 120-133. [CrossRef]

16. Devilbiss, D.M.; Waterhouse, B.D. Phasic and tonic patterns of locus coeruleus output differentially modulate sensory network function in the awake rat. J. Neurophysiol. 2011, 105, 69-87. [CrossRef]

17. Zerbi, V.; Floriou-Servou, A.; Markicevic, M.; Vermeiren, Y.; Sturman, O.; Privitera, M.; von Ziegler, L.; Ferrari, K.D.; Weber, B.; De Deyn, P.P.; et al. Rapid Reconfiguration of the Functional Connectome after Chemogenetic Locus Coeruleus Activation. Neuron 2019, 103, 702-718.e5. [CrossRef]

18. Chiew, K.S.; Braver, T.S. Temporal dynamics of motivation-cognitive control interactions revealed by high-resolution pupillometry. Front. Psychol. 2013, 4, 15. [CrossRef]

19. Van der Wel, P.; van Steenbergen, H. Pupil dilation as an index of effort in cognitive control tasks: A review. Psychon. Bull. Rev. 2018, 25, 2005-2015. [CrossRef]

20. Yebra, M.; Galarza-Vallejo, A.; Soto-Leon, V.; Gonzalez-Rosa, J.J.; de Berker, A.O.; Bestmann, S.; Oliviero, A.; Kroes, M.C.W.; Strange, B.A. Action boosts episodic memory encoding in humans via engagement of a noradrenergic system. Nat. Commun. 2019, 10, 3534. [CrossRef]

21. Gallant, S.N.; Kennedy, B.L.; Bachman, S.L.; Huang, R.; Lee, T.-H.; Mather, M. Behavioral and fMRI evidence that arousal enhances bottom-up attention and memory selectivity in young but not older adults. bioRxiv 2021, 1-45, preprint. [CrossRef]

22. Bland, A.R. Different varieties of uncertainty in human decision-making. Front. Neurosci. 2012, 6, 85. [CrossRef]

23. Darcq, E.; Kieffer, B.L. PI 3K signaling in the locus coeruleus: A new molecular pathway for ADHD research. EMBO Mol. Med. 2015, 7, 859-861. [CrossRef]

24. Bruno, K.J.; Freet, C.S.; Twining, R.C.; Egami, K.; Grigson, P.S.; Hess, E.J. Abnormal latent inhibition and impulsivity in coloboma mice, a model of ADHD. Neurobiol. Dis. 2007, 25, 206-216. [CrossRef]

25. Rowe, D.; Robinson, P.; Gordon, E. Stimulant drug action in attention deficit hyperactivity disorder (ADHD): Inference of neurophysiological mechanisms via quantitative modelling. Clin. Neurophysiol. 2005, 116, 324-335. [CrossRef]

26. McCall, J.G.; Siuda, E.R.; Bhatti, D.L.; Lawson, L.A.; McElligott, Z.A.; Stuber, G.D.; Bruchas, M.R. Locus coeruleus to basolateral amygdala noradrenergic projections promote anxiety-like behavior. Elife 2017, 6, e18247. [CrossRef]

27. Naegeli, C.; Zeffiro, T.; Piccirelli, M.; Jaillard, A.; Weilenmann, A.; Hassanpour, K.; Schick, M.; Rufer, M.; Orr, S.P.; Mueller-Pfeiffer, C. Locus coeruleus activity mediates hyperresponsiveness in posttraumatic stress disorder. Biol. Psychiatry 2018, 83, $254-262$. [CrossRef] 
28. Serova, L.I.; Nwokafor, C.; Van Bockstaele, E.J.; Reyes, B.A.; Lin, X.; Sabban, E.L. Single prolonged stress PTSD model triggers progressive severity of anxiety, altered gene expression in locus coeruleus and hypothalamus and effected sensitivity to NPY. Eur. Neuropsychopharmacol. 2019, 29, 482-492. [CrossRef]

29. Liu, K.Y.; Kievit, R.A.; Tsvetanov, K.A.; Betts, M.J.; Düzel, E.; Rowe, J.B.; Howard, R.; Hämmerer, D. Noradrenergic-dependent functions are associated with age-related locus coeruleus signal intensity differences. Nat. Commun. 2020, 11, 1712. [CrossRef] [PubMed]

30. Clewett, D.V.; Lee, T.-H.; Greening, S.; Ponzio, A.; Margalit, E.; Mather, M. Neuromelanin marks the spot: Identifying a locus coeruleus biomarker of cognitive reserve in healthy aging. Neurobiol. Aging 2016, 37, 117-126. [CrossRef]

31. Marcyniuk, B.; Mann, D.; Yates, P. Loss of nerve cells from locus coeruleus in Alzheimer's disease is topographically arranged. Neurosci. Lett. 1986, 64, 247-252. [CrossRef]

32. Olpe, H.-R.; Steinmann, M.W. Age-related decline in the activity of noradrenergic neurons of the rat locus coeruleus. Brain Res. 1982, 251, 174-176. [CrossRef]

33. Leslie, F.M.; Loughlin, S.E.; Sternberg, D.B.; McGaugh, J.L.; Young, L.E.; Zornetzer, S.F. Noradrenergic changes and memory loss in aged mice. Brain Res. 1985, 359, 292-299. [CrossRef]

34. Mueller, A.; Hong, D.S.; Shepard, S.; Moore, T. Linking ADHD to the neural circuitry of attention. Trends Cogn. Sci. 2017, 21, 474-488. [CrossRef] [PubMed]

35. Bachman, S.L.; Dahl, M.J.; Werkle-Bergner, M.; Düzel, S.; Forlim, C.G.; Lindenberger, U.; Kühn, S.; Mather, M. Locus coeruleus MRI contrast is associated with cortical thickness in older adults. Neurobiol. Aging 2021, 100, 72-82. [CrossRef]

36. Kempadoo, K.A.; Mosharov, E.V.; Choi, S.J.; Sulzer, D.; Kandel, E.R. Dopamine release from the locus coeruleus to the dorsal hippocampus promotes spatial learning and memory. Proc. Natl. Acad. Sci. USA 2016, 113, 14835-14840. [CrossRef]

37. Hoyer, R.S.; Elshafei, H.; Hemmerlin, J.; Bouet, R.; Bidet-Caulet, A. Why are children so distractible? Development of attention and motor control from childhood to adulthood. Child Dev. 2021, 92, e716-e737. [CrossRef]

38. Kannass, K.N.; Oakes, L.M.; Shaddy, D.J. A longitudinal investigation of the development of attention and distractibility. J. Cogn. Dev. 2006, 7, 381-409. [CrossRef]

39. Palfrey, J.S.; Levine, M.D.; Walker, D.K.; Sullivan, M. The emergence of attention deficits in early childhood: A prospective study. J. Dev. Behav. Pediatrics 1985, 6, 339-348. [CrossRef]

40. Liu, K.Y.; Acosta-Cabronero, J.; Cardenas-Blanco, A.; Loane, C.; Berry, A.J.; Betts, M.J.; Kievit, R.A.; Henson, R.N.; Duzel, E.; Cam, C.A.N.; et al. In vivo visualization of age-related differences in the locus coeruleus. Neurobiol. Aging 2019, 74, 101-111. [CrossRef]

41. Jacobs, H.I.L.; Muller-Ehrenberg, L.; Priovoulos, N.; Roebroeck, A. Curvilinear locus coeruleus functional connectivity trajectories over the adult lifespan: A 7T MRI study. Neurobiol. Aging 2018, 69, 167-176. [CrossRef]

42. Bondareff, W.; Mountjoy, C.Q.; Roth, M. Loss of neurons of origin of the adrenergic projection to cerebral cortex (nucleus locus ceruleus) in senile dementia. Neurology 1982, 32, 164-168. [CrossRef]

43. Casey, B.; Heller, A.S.; Gee, D.G.; Cohen, A.O. Development of the emotional brain. Neurosci. Lett. 2019, 693, 29-34. [CrossRef]

44. Toga, A.W.; Thompson, P.M.; Sowell, E.R. Mapping brain maturation. Focus 2006, 29, 148-390.

45. Nomi, J.S.; Bolt, T.S.; Ezie, C.C.; Uddin, L.Q.; Heller, A.S. Moment-to-moment BOLD signal variability reflects regional changes in neural flexibility across the lifespan. J. Neurosci. 2017, 37, 5539-5548. [CrossRef]

46. Elliott, M.L.; Knodt, A.R.; Cooke, M.; Kim, M.J.; Melzer, T.R.; Keenan, R.; Ireland, D.; Ramrakha, S.; Poulton, R.; Caspi, A. General functional connectivity: Shared features of resting-state and task fMRI drive reliable and heritable individual differences in functional brain networks. NeuroImage 2019, 189, 516-532. [CrossRef]

47. Lee, T.-H.; Miernicki, M.E.; Telzer, E.H. Behavioral and neural concordance in parent-child dyadic sleep patterns. Dev. Cogn. Neurosci. 2017, 26, 77-83. [CrossRef]

48. Lee, T.-H.; Miernicki, M.E.; Telzer, E.H. Families that fire together smile together: Resting state connectome similarity and daily emotional synchrony in parent-child dyads. NeuroImage 2017, 152, 31-37. [CrossRef]

49. Lee, T.-H.; Telzer, E.H. Negative functional coupling between the right fronto-parietal and limbic resting state networks predicts increased self-control and later substance use onset in adolescence. Dev. Cogn. Neurosci. 2016, 20, 35-42. [CrossRef]

50. Nooner, K.B.; Colcombe, S.; Tobe, R.; Mennes, M.; Benedict, M.; Moreno, A.; Panek, L.; Brown, S.; Zavitz, S.; Li, Q. The NKI-Rockland sample: A model for accelerating the pace of discovery science in psychiatry. Front. Neurosci. 2012, 6, 152. [CrossRef]

51. Landis, D.; Courtney, W.; Dieringer, C.; Kelly, R.; King, M.; Miller, B.; Wang, R.; Wood, D.; Turner, J.A.; Calhoun, V.D. COINS Data Exchange: An open platform for compiling, curating, and disseminating neuroimaging data. NeuroImage 2016, 124, 1084-1088. [CrossRef]

52. Pruim, R.H.; Mennes, M.; van Rooij, D.; Llera, A.; Buitelaar, J.K.; Beckmann, C.F. ICA-AROMA: A robust ICA-based strategy for removing motion artifacts from fMRI data. NeuroImage 2015, 112, 267-277. [CrossRef]

53. Avants, B.B.; Tustison, N.J.; Stauffer, M.; Song, G.; Wu, B.; Gee, J.C. The Insight ToolKit image registration framework. Front. Neuroinformatics 2014, 8, 44. [CrossRef]

54. Keren, N.I.; Lozar, C.T.; Harris, K.C.; Morgan, P.S.; Eckert, M.A. In vivo mapping of the human locus coeruleus. NeuroImage 2009, 47, 1261-1267. [CrossRef]

55. Winkler, A.M.; Ridgway, G.R.; Webster, M.A.; Smith, S.M.; Nichols, T.E. Permutation inference for the general linear model. Neuroimage 2014, 92, 381-397. [CrossRef] [PubMed] 
56. Wang, Q.; Gao, E.; Burkhalter, A. Gateways of ventral and dorsal streams in mouse visual cortex. J. Neurosci. 2011, 31, 1905-1918. [CrossRef]

57. Burton, H.; Sinclair, R.J.; Wingert, J.R.; Dierker, D.L. Multiple parietal operculum subdivisions in humans: Tactile activation maps. Somatosens. Mot. Res. 2008, 25, 149-162. [CrossRef]

58. Warrier, C.; Wong, P.; Penhune, V.; Zatorre, R.; Parrish, T.; Abrams, D.; Kraus, N. Relating structure to function: Heschl's gyrus and acoustic processing. J. Neurosci. 2009, 29, 61-69. [CrossRef]

59. Kovach, C.K.; Daw, N.D.; Rudrauf, D.; Tranel, D.; O'Doherty, J.P.; Adolphs, R. Anterior prefrontal cortex contributes to action selection through tracking of recent reward trends. J. Neurosci. 2012, 32, 8434-8442. [CrossRef]

60. Sowell, E.R.; Thompson, P.M.; Toga, A.W. Mapping changes in the human cortex throughout the span of life. Neuroscientist 2004, 10, 372-392. [CrossRef]

61. Poe, G.R.; Foote, S.; Eschenko, O.; Johansen, J.P.; Bouret, S.; Aston-Jones, G.; Harley, C.W.; Manahan-Vaughan, D.; Weinshenker, D.; Valentino, R. Locus coeruleus: A new look at the blue spot. Nat. Rev. Neurosci. 2020, 21, 644-659. [CrossRef]

62. Mattson, M.P.; Arumugam, T.V. Hallmarks of Brain Aging: Adaptive and Pathological Modification by Metabolic States. Cell Metab. 2018, 27, 1176-1199. [CrossRef] [PubMed]

63. Nyberg, L.; Salami, A.; Andersson, M.; Eriksson, J.; Kalpouzos, G.; Kauppi, K.; Lind, J.; Pudas, S.; Persson, J.; Nilsson, L.G. Longitudinal evidence for diminished frontal cortex function in aging. Proc. Natl. Acad. Sci. USA 2010, 107, 22682-22686. [CrossRef] [PubMed]

64. Salat, D.H.; Buckner, R.L.; Snyder, A.Z.; Greve, D.N.; Desikan, R.S.; Busa, E.; Morris, J.C.; Dale, A.M.; Fischl, B. Thinning of the cerebral cortex in aging. Cereb. Cortex 2004, 14, 721-730. [CrossRef] [PubMed]

65. Cliff, M.; Joyce, D.W.; Lamar, M.; Dannhauser, T.; Tracy, D.K.; Shergill, S.S. Aging effects on functional auditory and visual processing using fMRI with variable sensory loading. Cortex 2013, 49, 1304-1313. [CrossRef]

66. Hämmerer, D.; Callaghan, M.F.; Hopkins, A.; Kosciessa, J.; Betts, M.; Cardenas-Blanco, A.; Kanowski, M.; Weiskopf, N.; Dayan, P.; Dolan, R.J.; et al. Locus coeruleus integrity in old age is selectively related to memories linked with salient negative events. Proc. Natl. Acad. Sci. USA 2018, 115, 2228-2233. [CrossRef]

67. Sudre, G.; Szekely, E.; Sharp, W.; Kasparek, S.; Shaw, P. Multimodal mapping of the brain's functional connectivity and the adult outcome of attention deficit hyperactivity disorder. Proc. Natl. Acad. Sci. USA 2017, 114, 11787-11792. [CrossRef]

68. Prado, J.; Carp, J.; Weissman, D.H. Variations of response time in a selective attention task are linked to variations of functional connectivity in the attentional network. NeuroImage 2011, 54, 541-549. [CrossRef]

69. Hart, H.; Radua, J.; Nakao, T.; Mataix-Cols, D.; Rubia, K. Meta-analysis of functional magnetic resonance imaging studies of inhibition and attention in attention-deficit/hyperactivity disorder: Exploring task-specific, stimulant medication, and age effects. JAMA Psychiatry 2013, 70, 185-198. [CrossRef]

70. Kam, J.W.Y.; Lin, J.J.; Solbakk, A.K.; Endestad, T.; Larsson, P.G.; Knight, R.T. Default network and frontoparietal control network theta connectivity supports internal attention. Nat. Hum. Behav. 2019, 3, 1263-1270. [CrossRef]

71. Corbetta, M.; Patel, G.; Shulman, G.L. The reorienting system of the human brain: From environment to theory of mind. Neuron 2008, 58, 306-324. [CrossRef]

72. Alakörkkö, T.; Saarimäki, H.; Glerean, E.; Saramäki, J.; Korhonen, O. Effects of spatial smoothing on functional brain networks. Eur. J. Neurosci. 2017, 46, 2471-2480. [CrossRef]

73. Wengler, K.; He, X.; Abi-Dargham, A.; Horga, G. Reproducibility assessment of neuromelanin-sensitive magnetic resonance imaging protocols for region-of-interest and voxelwise analyses. NeuroImage 2020, 208, 116457. [CrossRef]

74. Betts, M.J.; Kirilina, E.; Otaduy, M.C.G.; Ivanov, D.; Acosta-Cabronero, J.; Callaghan, M.F.; Lambert, C.; Cardenas-Blanco, A.; Pine, K.; Passamonti, L.; et al. Locus coeruleus imaging as a biomarker for noradrenergic dysfunction in neurodegenerative diseases. Brain 2019, 142, 2558-2571. [CrossRef]

75. Watanabe, T.; Tan, Z.; Wang, X.; Martinez-Hernandez, A.; Frahm, J. Magnetic resonance imaging of noradrenergic neurons. Brain Struct. Funct. 2019, 224, 1609-1625. [CrossRef]

76. Plini, E.R.G.; O’Hanlon, E.; Boyle, R.; Sibilia, F.; Rikhye, G.; Kenney, J.; Whelan, R.; Melnychuk, M.C.; Robertson, I.H.; Dockree, P.M. Examining the Role of the Noradrenergic Locus Coeruleus for Predicting Attention and Brain Maintenance in Healthy Old Age and Disease: An MRI Structural Study for the Alzheimer's Disease Neuroimaging Initiative. Cells 2021, 10, 1829. [CrossRef]

77. Dahl, M.J.; Mather, M.; Werkle-Bergner, M.; Kennedy, B.L.; Guzman, S.; Hurth, K.; Miller, C.A.; Qiao, Y.; Shi, Y.; Chui, H.C.; et al. Locus coeruleus integrity is related to tau burden and memory loss in autosomal-dominant Alzheimer's disease. medRxiv 2021. preprint. [CrossRef]

78. Betts, M.J.; Cardenas-Blanco, A.; Kanowski, M.; Jessen, F.; Duzel, E. In vivo MRI assessment of the human locus coeruleus along its rostrocaudal extent in young and older adults. NeuroImage 2017, 163, 150-159. [CrossRef]

79. Tona, K.D.; Keuken, M.C.; de Rover, M.; Lakke, E.; Forstmann, B.U.; Nieuwenhuis, S.; van Osch, M.J.P. In vivo visualization of the locus coeruleus in humans: Quantifying the test-retest reliability. Brain Struct. Funct. 2017, 222, 4203-4217. [CrossRef]

80. Ye, R.; Rua, C.; O'Callaghan, C.; Jones, P.S.; Hezemans, F.H.; Kaalund, S.S.; Tsvetanov, K.A.; Rodgers, C.T.; Williams, G.; Passamonti, L.; et al. An in vivo probabilistic atlas of the human locus coeruleus at ultra-high field. NeuroImage 2021, $225,117487$. [CrossRef]

81. Glover, G.H.; Li, T.Q.; Ress, D. Image-based method for retrospective correction of physiological motion effects in fMRI: RETROICOR. Magn. Reson. Med. 2000, 44, 162-167. [CrossRef] 